\title{
The utilization of edge-of-field monitoring of agricultural runoff in addressing nonpoint source pollution
}

\author{
M.B. Daniels, A. Sharpley, R.D. Harmel, and K. Anderson
}

\begin{abstract}
While basin-scale studies and modeling are important tools in relating land uses to water quality concerns, edge-of-field monitoring (EOFM) provides the necessary resolution to spatially target, design, and evaluate in-field conservation practices for reducing nonpoint source pollution from agriculture. This paper introduces this special issue of the Journal of Soil and Water Conservation, a collection that provides an overview of EOFM on agricultural lands. The issue describes the transition of EOFM from a mainly research endeavor to on-farm monitoring of the environmental impact and performance of agricultural practices and addresses topics such as (1) disconnect between large-scale loading estimates and the prevalence of sound nutrient management practices; (2) obstacles in identifying the causes, sources, and solutions to agricultural nonpoint source pollution; (3) progress evaluation at the watershed scale; (4) need for additional multiscale studies to better understand the fate and transport continuum and establish linkages between EOFM and in-stream water quality; (5) history of EOFM and recent advances; and (6) alternative methods to determine whether EOF results are acceptable. The increased attention on agricultural runoff has concurrently raised awareness of the need for EOFM. It is at the field scale that data are needed to better understand the fate of sediment and applied nutrients and inform adaptive management to mitigate offsite losses. This special issue compiles the latest scientific information related to utilizing EOFM to evaluate and address agricultural nonpoint sources, and provides a glimpse of EOFM in the future.
\end{abstract}

Key words: agricultural management—conservation assessment-monitoring-nutrient runoff-water quality

Nutrient enrichment continues to be a major impairment to the designated uses of fresh and coastal waters of the United States (Schindler et al. 2008; Milachak et al. 2013; Kleinman et al. 2015). Prominent water quality issues, such as harmful algae blooms in Lake Erie (NOAA 2017a) and a large hypoxic zone in the northern Gulf of Mexico (NOAA 2017b), have prompted unparalleled activity in developing action plans to correct these issues (Mississippi River/Gulf of Mexico Watershed Nutrient Task Force 2008; Great Lakes Interagency Task Force 2017). These plans have included modeling efforts and basin-scale studies to geographically identify the source, as well as estimate the relative nutrient loading, as a foundation for setting reduction goals and developing corrective actions (Alexander et al. 2008; White et al. 2014; Tomer 2018).
For instance, the 2008 action plan for the Gulf of Mexico set an interim nutrient reduction goal of $20 \%$ by 2025 . In this issue, Baker et al. (2018) provide an overview of that action plan. The 2011 to 2014 plan for the Great Lakes was recently presented to Congress and contains detailed action items and performance measures. Several papers in this issue provide information on the Great Lakes, and specifically, on Lake Erie (Kalcic et al. 2018; King et al. 2018; Smith et al. 2018). While there are many sources of nutrients, studies commissioned with these action plans have estimated that agriculture, in particular intensive livestock and crop production, is a major contributor of nutrients to both the Great Lakes and Gulf of Mexico.

Recent model estimates from the Spatially Referenced Regressions on Watershed attributes model (SPARROW) suggest that up to $85 \%$ of the phosphorus $(\mathrm{P})$ and nitrogen $(\mathrm{N})$ entering the Gulf of Mexico originates from agriculture (Alexander et al. 2008). Modeling results from White et al. (2014) also indicate that cultivated agriculture was the largest source of nutrients to the Gulf but that point sources contributed substantial P loading. Robertson and Saad (2011) used SPARROW to estimate that $58 \%$ of the $\mathrm{N}$ and $33 \%$ to $44 \%$ of $\mathrm{P}$ delivered to Lake Erie originates from agriculture, and that $26 \%$ of the total nutrient load originates from crop land receiving inorganic fertilizer.

Others have used historical tributary stream and lake water quality monitoring data coupled with stream flow approximations to systematically estimate nutrient loadings from the upper reaches of tributaries to the lakes. Smith et al. (2018) reviewed literature on potential sources of nutrients in the Maumee River in the western Lake Erie Basin, including papers from Maccoux et al. (2016) that found $71 \%$ of $\mathrm{P}$ loading to Lake Erie originated from nonpoint sources. Scavia et al. (2016) estimated that the Maumee River, whose watershed's land use is largely row crop agriculture, transported an estimated $85 \%$ of the $\mathrm{P}$ transported into Lake Erie. While these modeling efforts and nutrient loading estimates provide a directionally correct step in identifying potential nutrient sources and subwatersheds posing the greatest concern, they fall short in spatially pinpointing the source at a scale that agriculture can address. The models also provide insight to the most effective corrective actions but often do not identify definitive answers as to which practices implemented in which locations will produce the desired results.

Effectively minimizing nutrient loss from agricultural landscapes requires (1) identification of nutrient source locations; (2) estimation of nutrient loss amounts and tim-

Mike B. Daniels is a professor of Extension water quality at the University of Arkansas, Division of Agriculture, Little Rock, Arkansas. Andrew Sharpley is a distinguished professor with the Department of Crops, Soils and Environmental Sciences, University of Arkansas, Division of Agriculture, Fayetteville, Arkansas. R. Daren Harmel is director of the Center for Agricultural Resources Research, USDA Agricultural Research Service, Fort Collins, Colorado. Karma Anderson is leader of the National Water Quality and Quantity Team with USDA Natural Resources Conservation Service, Portland, Oregon. 
ing from a field to receiving water body; (3) determination of what conservation practices (CPs) are effective and practical; and (4) monitoring to quantify $\mathrm{CP}$ effectiveness, so that adaptive management can account for the dynamic nature of living ecosystems.

Edge-of-field monitoring (EOFM) of runoff from individual agricultural fields has been identified as critical to improve our understanding of the fate and transport of nutrients applied as animal manures and fertilizer to agricultural lands along the complex watershed continuum (Reba et al. 2013; Harmel et al. 2016; Sharpley et al. 2016b). This understanding will lead to more effective reduction strategies by allowing remedial measures to be implemented in a more spatially explicit manner to meet local hydrologic and crop production conditions.

This introductory paper provides an overview of EOFM and the latest scientific information derived from EOFM, as well as the transition from research to more routine monitoring of environmental impact and performance of agricultural practices. The paper also provides a roadmap to the articles in this special issue dedicated to EOFM.

\section{Role of Edge-of-Field Monitoring in Estimating Field-Scale Nutrient Contribution to Downstream Waters}

Nutrient load estimates based on basin-scale modeling or hydrological estimation techniques that endeavor to relate ambient water quality data to spatially explicit land uses can have significant uncertainty. Edge-of-field runoff studies of $\mathrm{P}$ and $\mathrm{N}$ loss from agricultural production systems in the Mississippi River Basin (Kröger et al. 2012) and the Great Lakes region have produced more than 700 site years of data according to Harmel et al. (2016). However, broad-scale estimates for the most part have provided the foundation for developing nutrient reduction goals and strategies at a basin or watershed scale (Tomer 2018).

The modeling and methodology described above have similar traits as they both rely on in-stream or in-lake water quality sampling of nutrients. In a sense, they backtrack from the observed in-waterbody nutrient concentrations by systematically tracing nutrient paths from upstream tributaries and their watersheds using either modeling or hydrological load estimates. While these techniques can target subwatersheds of concern, they do not necessarily define the actual source, only the general location.
For example, the SPARROW model uses empirical regression techniques, and other models use generalized relations, to relate land use and management to downstream water quality; however, temporal and spatial variability in factors such as land use/management, topography, and hydrology create a high degree of uncertainty in model predictions (Shirmohammadi et al. 2006; Harmel et al.2010). Decisions and strategies based on modeling results often overlook the uncertainty because few options are available to effectively address it, although this is changing (Harmel et al. 2014).

Estimating nutrient loads by combining in-waterbody nutrient concentrations with flow estimates can also help trace back to a subwatershed of concern but provide little insight into the actual source. Often spatially explicit land use and land cover data within a watershed is empirically regressed with in-waterbody flow-weighted nutrient concentrations to define a category of source such as urban, agriculture, or point sources (Haggard 2010; Veith et al. 2015). Kalcic et al. (2018) provide an excellent synthesis of the limitations of watershed models such as the Soil and Water Assessment Tool (SWAT) and Agricultural Policy Environmental EXtender (APEX), which attempt to relate land use to EOF water quality.

Kalcic et al. (2018) also point out that differences in geographical scale in defining a water quality issue, and the scale at which the solution should be applied or defined, can create disconnects in determining progress toward a stated goal. Agricultural producers often focus on the field or farm scale where they make management decisions. In contrast, agency personnel focus on larger watersheds and/or multiple watershed scales, and often policy makers focus on political rather than hydrological boundaries.

Kalcic et al. (2018) also provide further information on the issue of scale and cite a study reviewing the USDA-funded Conservation Effects Assessment Project (CEAP), which sought to detect water quality improvements from conservation actions in over a dozen watersheds across the United States (Tomer and Locke 2011; Osmond et al. 2012). This work highlighted the difficulty in applying field-scale solutions across a watershed and most importantly, reliably monitoring performance at a watershed scale. Issues such as the lag times between implementation of conservation actions and response of environmental indicators in streams often mask any immediate gain in reduction and may take years of in-waterbody monitoring to detect improvement (Sharpley et al. 2009). For example, in-stream concentrations of $\mathrm{P}$ can be influenced for years by preexisting $\mathrm{P}$, or legacy $\mathrm{P}$, which can also mask the effectiveness of CPs at the watershed scale (Sharpley et al. 2013).

Baker et al. (2018) monitored paired watersheds to investigate the effect of CPs but found that the variability in sediment and nutrient data limited the ability to determine performance. They felt an improvement in design that would utilize EOFM was needed to isolate sediment and nutrient load data from specific land use areas and account for nutrient application data specific to the aforementioned land use areas. Having information from both the EOF and small watershed scale would enable determination of field-scale nutrient and sediment mass balances, allowing a more accurate estimation of nutrient retention by CPs and nutrient loss to downstream waters (Baker et al. 2018). Further, Tomer (2018) suggests a "twice-paired" watershed experiment design to measure the benefits of combined CPs for water quality improvement. Here, a pair of EOF practices (e.g., denitrifying bioreactors, buffer strips) would be installed below two similarly managed fields and monitored for a few years. Inflow and outflow data provides a calibration of the hydrology and water quality between the two fields and EOF practices. After this calibration period, an in-field CP is installed on one of the two fields and monitoring continued (Tomer 2018).

Modeling and hydrological source tracking can provide guidance on general geographical location and on the potential source, but it may not identify the corrective actions to reduce the source at a particular location, except with educated, sophisticated guesses (Sharpley et al. 2010). Yet, due to the lack of data and understanding of how nutrients move from agricultural landscapes, nutrient reduction strategies often assume the corrective action matches the particular agricultural field. In addition, in many cases, the remedial strategies are based on a few key corrective actions, which are blanketed across agricultural landscapes, in hopes they specifically address the targeted source on enough acres to obtain a substantial nutrient load reduction.

To summarize, identifying sources with models and other techniques at one scale, 
but implementing solutions at another and then monitoring progress at another scale, creates a disconnect (Sharpley et al. 2016b). This disconnect between on-the-ground corrective action at a limited number of land uses or managed field units and monitoring of performance measures at a watershed scale, must clearly be addressed. For example, Smith et al. (2018) reviewed studies that suggested the predominant land use, agriculture, in the Maumee River watershed is a major contributor of $\mathrm{P}$ to western Lake Erie. They reviewed survey results of row crop farmers in the Maumee River watershed and found many farmers use science-based nutrient management recommendations with regard to soil testing as a guide for P fertilizer applications. Their results showed that in over $90 \%$ of the fields surveyed, P fertilizer applications either met or were below fertilizer recommendations from soil testing (Smith et al. 2018). Ultimately, the survey indicated that many producers had voluntarily implemented, at some level, scientifically appropriate $\mathrm{P}$ management practices, yet the anticipated benefits have yet to be realized.

Thus, faced with these challenges, how do we appropriately use modeling and monitoring and at what scale to address the problem of excess nutrient loading? Both of these tools are necessary, since neither provides all the information needed to address the problem (table 1). Stakeholders typically place more trust in measured data; however, there are never enough data because data are expensive and time-consuming to collect and because they cannot cover all spatial and temporal scales and hydroclimatic conditions. Models are less expensive and produce more rapid estimates, but they also rely on measured data to provide confidence in predictions. Models are also the only tools capable of simulating alternative practices, spatial relationships, various conditions, and future scenarios. To address the problem of excess nutrient loading requires determining the important sources, and their relative contributions, the CPs to implement, where to install CPs, and post-implementation effectiveness of CPs.

\section{Utilizing Edge-of-Field Monitoring to Evaluate and Address Agricultural Sources} Edge-of-field monitoring facilitates (1) quantification of nutrient and sediment losses from individual management units such as fields; (2) testing of CP efficacy for a given set of conditions; (3) better understanding of the complex, biological, chemical, and physical relationships that determine the fate of sediment and nutrients applied as fertilizer; (4) more robust models at the field scale that can be linked to larger regional models; and most importantly, (5) involvement of producers in solution development.

Within the last decade, EOFM has moved from mostly research applications to routine adoption for education and performance assessment of environmental indicators on real, working farms. Research scientists have been conducting EOFM for decades, but advances in automated sampling technology have made it more practical for routine monitoring as described by Harmel et al. (2018a). The USDA's Agricultural Research Service has been a leader in conducting EOFM research in Ohio, Iowa, Texas, Missouri, and other states. For instance, King et al. (2018) utilized a network of 40 EOF sites to evaluate the $4 \mathrm{Rs}$ of fertilizer management ("right source, right rate, right time, and right place") that are being promoted by the fertilizer industry to address nutrient loss from agricultural fields (Nutrient Stewardship 2017). The results highlight the importance of understanding field hydrology on surface and subsurface $\mathrm{P}$ transport. The authors also point out that the effectiveness of the nutrient management practices will likely vary across fields with different characteristics.

The nutrient runoff effectiveness of CPs on private farms in Arkansas is being evaluated by the Arkansas Discovery Farm Program (Sharpley et al. 2015, 2016a; University of Arkansas Division of Agriculture 2017). Monitoring nutrient inflow and outflow into and out of a $300 \mathrm{~m}$ grassed waterway (Natural Resources Conservation Service [NRCS] CP 412) between 2013 and 2016 demonstrated its effectiveness in decreasing $\mathrm{N}$ and $\mathrm{P}$ runoff around poultry production facilities (figure 1a). For 2013, 2014, and 2015 , the grassed waterway decreased run-

\section{Table 1}

Role of edge-of-field (EOF) monitoring and modeling tools in addressing nitrogen (N) and phosphorus (P) loading to downstream waters.

\begin{tabular}{|c|c|}
\hline Step & Tools \\
\hline Determine sources & $\begin{array}{l}\text { - Gather site-specific measured data at the field, farm, and watershed scale. } \\
\text { - Use model to determine sources in absence of measured data (best professional judgement and } \\
\text { stakeholder input can be valuable as well). }\end{array}$ \\
\hline Estimate source contribution & $\begin{array}{l}\text { - Use measured EOF runoff data to estimate field-scale N and P losses. In the absence of site-specific } \\
\text { data for agricultural (cultivated and pasture/range), forest, and drainage contributions, see the MANAGE data- } \\
\text { base (Harmel et al. 2008, 2016). } \\
\text { - Use end-of-pipe data for point sources. } \\
\text { - Use measured in-stream data and models to estimate fate and transport. }\end{array}$ \\
\hline $\begin{array}{l}\text { Determine type(s) and location(s) of } \\
\text { conservation practices (CPs) }\end{array}$ & $\begin{array}{l}\text { - Use measured EOF and small watershed data and models to optimize practice type and location on fields, } \\
\text { farms, and small watersheds with the largest loading and/or where the practice(s) will be more effective. }\end{array}$ \\
\hline Evaluate effectiveness & $\begin{array}{l}\text { - Use measured EOF and downstream data and multiyear time frame to assess effectiveness, if adequate } \\
\text { funding is available. } \\
\text { - Use model if a more rapid estimate is required or in the absence of funding for monitoring. }\end{array}$ \\
\hline If necessary conduct research & - Use field or laboratory studies to improve models and better understand processes. \\
\hline use additional CPs & $\begin{array}{l}\text { - Determine whether additional CPs are needed based on monitoring data, improved scientific understanding, } \\
\text { and refined model predictions. }\end{array}$ \\
\hline
\end{tabular}




\section{Figure 1}

(a) Effectiveness of grassed waterway to decrease runoff, nitrogen $(\mathrm{N})$, and phosphorus $(\mathrm{P})$ loss from poultry operations and (b) percentage of applied $\mathrm{N}$ and $\mathrm{P}$ in edge-of-field runoff under cotton-corn rotation (adapted from Sharpley et al. [2015]).
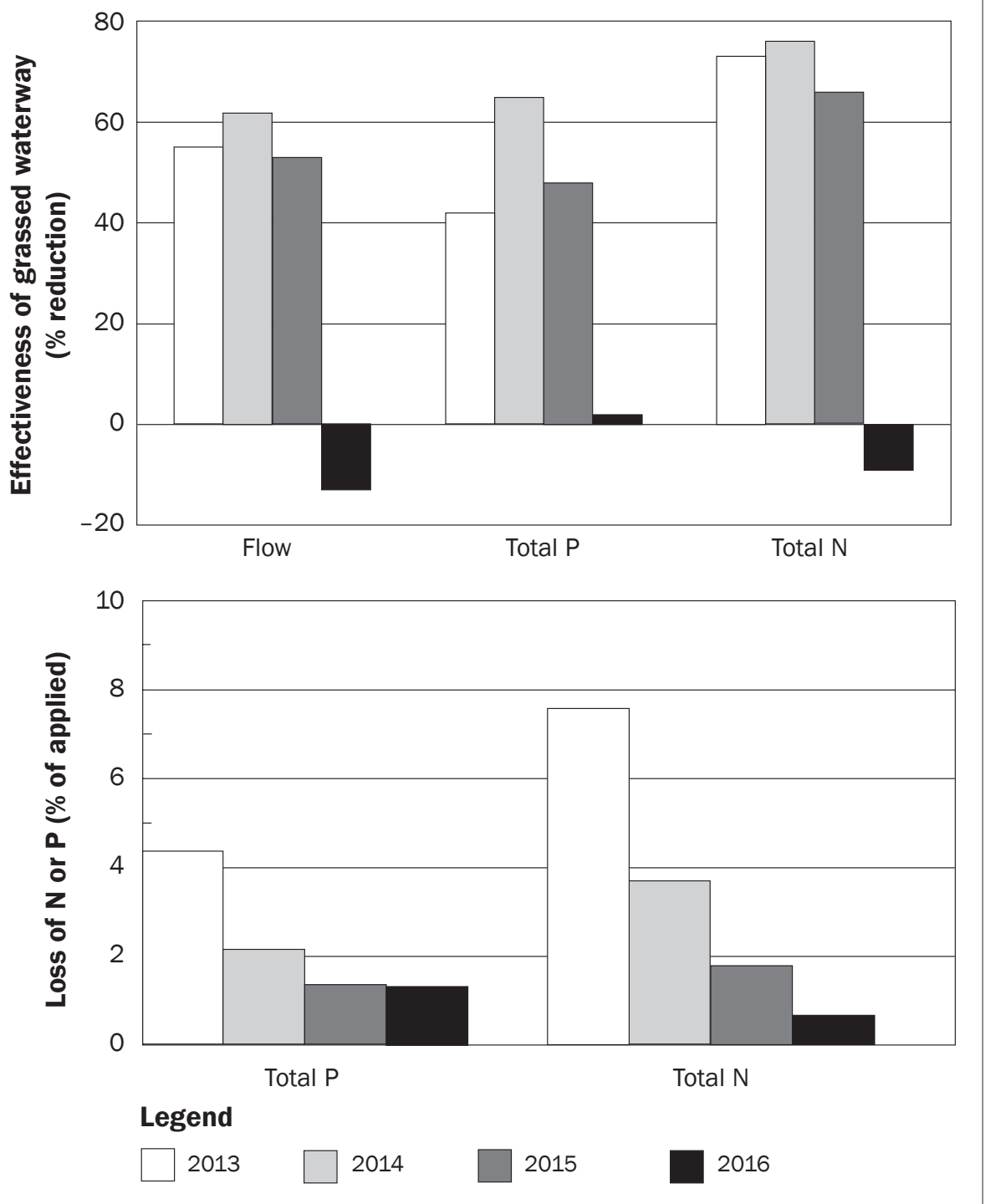

off by over $50 \%$ (i.e., the difference between inflow and outflow volumes). In 2016, fewer, more intense rainfalls occurred $(8$ runoff events averaging $42.6 \mathrm{~mm}$ ) than in 2013 (16 runoff events averaging $35.7 \mathrm{~mm}$ ), 2014 (13 runoff events averaging $36.1 \mathrm{~mm}$ ), and 2015 (19 runoff events averaging $33.7 \mathrm{~mm}$ ), which exceeded the ability of the grassed waterway to mitigate runoff volumes. In fact, 2016 runoff increased between upstream and downstream sites (figure 1a). A similar trend of decreasing total N (66\% to $76 \%)$ and total $\mathrm{P}(42 \%$ to $65 \%)$ runoff was found for 2013 to 2015 (figure 1a). In 2016, the grassed filter strip was a slight source of total $\mathrm{N}$ (figure 1a).

The other example of $\mathrm{CP}$ effectiveness demonstrated by the Arkansas Discovery
Farm Program is the use of cover crops (NRCS CP 340) on cotton (Gossypium hirsutum L.)-corn (Zea mays L.) rotations (Sharpley et al. 2015, 2016a). The loss of total $\mathrm{N}$ applied as fertilizer to these fields decreased from $7.6 \%$ (2013) to $0.7 \%$ (2016) and for $\mathrm{P}$ from $4.3 \%$ to $1.3 \%$, respectively (figure 1b). These trends demonstrate another important consideration in the $\mathrm{CP}$ effectiveness and EOF losses, in that most structural and source-mediated CPs take time to achieve maximum reduction potentials. Clearly, these CPs can decrease nutrient runoff, but under high, intense rainfalls, their effectiveness is diminished. Aryal et al. (2018) also evaluated the effectiveness of cover crops in reducing nutrients and sed- iment losses and changes in runoff water quality from irrigation tailwater and rainfall runoff in an EOFM project with two paired, field-scale sites in Arkansas. Winter cover crops effectively reduced nitrate-N $\left(\mathrm{NO}_{3}-\mathrm{N}\right)$ concentrations by $86 \%$ and phosphate-P $\left(\mathrm{PO}_{4}-\mathrm{P}\right)$ by $53 \%$ at one site, but the other site yielded similar nutrient runoff with and without cover crops. Nutrient and sediment losses were generally higher during the nongrowing season (November to April) than during growing season (May to October), which indicates the importance of CPS to nutrient and sediment losses in the winter. The authors also determined that runoff water quality generated by irrigation was not different from rainfall runoff.

\section{Incorporating Edge-of-Field Monitoring in Educational and Financial Assistance Programs}

Land grant universities have been conducting EOFM for research and assessment, but during the last decade or so have developed programs to extend EOFM to real, working farms for outreach and education. A notable example is the Discovery Farm Program, which originated in Wisconsin (University of Wisconsin Extension 2017), but programs have spread to others states, such as Minnesota (Minnesota Agricultural Water Resources Center 2017), North Dakota (North Dakota State University 2017), and Arkansas (University of Arkansas Division of Agriculture 2017). While EOFM is at the core of data collection, the real power of this program is providing farmers opportunities for leadership in addressing water quality issues. For example, Discovery farmers can make decisions based on real data and find solutions that meet their conditions on their farm and for their situation. More importantly, it empowers farmers to educate other farmers, which brings awareness, credibility, and new solutions. Other programs that utilize EOFM and farmer educational networks include Mississippi State's Research and Education to Advance Conservation and Habitat (Mississippi State University 2017) and Louisiana's Master Farmer Program (Louisiana Agricultural Center 2017).

Additionally, the USDA NRCS has recognized the power of EOFM (USDA NRCS 2013a, 2013b) in evaluating the effect of the CPs and routinely provides financial incentives for adoption. NRCS first piloted EOFM within the Mississippi River Basin Healthy 
Watersheds Initiative in 2010 and 2011 using the Monitoring and Evaluation (799) interim conservation practice standard (CPS). In 2013, NRCS, with input from other technical professionals, developed two new conservation activities: Edge-of-Field Water Quality Monitoring-Data Collection and Evaluation (201) and Edge-of-Field Water Quality Monitoring-System Installation (202). The objectives of these two conservation activities are to (1) evaluate conservation system performance; (2) validate and calibrate models, and (3) inform on-farm adaptive management. Conservation activities 201 and 202 are more stringent than CPS 799 and are designed to deliver scientifically sound data to NRCS for model improvement and to provide feedback to the producer on the effectiveness of CPs in reducing nutrient and sediment impacts to surface water.

The USDA NRCS conservation activities are funded through the Environmental Quality Incentives Program, where funding is provided to the landowner who then partners with a monitoring professional to implement monitoring, analyze data, and evaluate the effectiveness of CPs on a particular field. NRCS then utilizes the data to validate its conservation models and evaluate trends within a watershed. However, this approach is unique in that it directly involves the landowner in the monitoring effort on their own land, providing valuable feedback on his or her management system. Additionally, NRCS is bound by confidentiality rules, which prohibit NRCS from sharing monitoring data. If a landowner chooses to do so, he or she may share the data with others, but NRCS will not. To date, NRCS has provided funding of nearly US $\$ 6.3$ million for over 40 projects in 10 states, nationwide. In Arkansas, NRCS is working closely with the Arkansas Discovery Farm to document and promote the benefits of conservation.

In a relatively short period, EOFM has evolved as a research concept and tool to a routine practice to document runoff water quality on real, working farms. Researchers will continue to improve the process of EOFM as these data help empower farmers to become leaders and educators of their fellow farmers in addressing water quality. Nutrient reduction from agriculture has a greater probability of success when agricultural producers are involved in the initial design of solutions. Further, data collected from EOFM allows them to see firsthand the performance and impact of management actions on their land or their neighbors' land. Many nutrient reduction approaches have completely left the agricultural producer out of the solution design, which may limit adoption. Efforts such as NRCS' conservation activities 201 and 202 are providing a catalyst for more widespread collection of EOF data, which in turn will help the performance of models in targeting and addressing nonpoint source pollution.

\section{What Are Considered Acceptable Losses and Uncertainty in Edge-of-Field Monitoring?}

Excess nutrient loading continues to adversely impact water resources, and determination of the cause(s) of accelerated nutrient enrichment has become a contentious and litigious issue in the United States. Despite this, one fundamental question that remains unanswered is what should be considered acceptable levels of nutrients in runoff from agricultural fields. Failing to consider this question, recognizing that some level of nutrient loss is unavoidable from natural and anthropogenic sources, hinders on-farm management as well as policy

\section{Table 2}

Mean annual loss of nitrogen $(\mathrm{N})$ and phosphorus $(\mathrm{P})$ in runoff with differing land use as a function of $\mathrm{N}$ and $\mathrm{P}$ applied in fertilizer for the 2013 to 2016 edge-of-field (EOF) monitoring period (adapted from Sharpley et al. [2015]).

\begin{tabular}{lll}
\hline Land use & Nutrient loss $\left.\mathbf{( k g ~ h a - 1} \mathbf{y}^{-\mathbf{1}}\right)$ & Applied loss in runoff (\%) \\
\hline Nitrogen & & 1.5 \\
Corn & 1.9 & 4.6 \\
Cotton & 6.7 & 0.2 \\
Pasture & 0.6 & 1.3 \\
Soybean & 3.6 & \\
Predicted nutrient loss & 27.3 & \\
Trading eligibility threshold & 15.0 & \\
Range of Discovery EOF sites* & 0.5 to 11.8 & 1.5 \\
Average Discovery EOF sites $\dagger$ & 3.2 & 2.8 \\
Phosphorus & & 0.2 \\
Corn & 0.4 & 1.6 \\
Cotton & 1.0 & \\
Pasture & 0.2 & \\
Soybean & 1.2 & \\
Predicted nutrient loss & 3.6 & \\
Trading eligibility threshold & 2.0 & \\
Range of Discovery EOF sites* & $<0.1$ to 2.8 \\
Average Discovery EOF sites $\dagger$ & 0.8 & \\
* Range in annual nutrient loss from 20 Discovery Farm edge-of-field (EOF) sites between 2013 \\
and 2016.
\end{tabular}
al. (2018b) explore this issue.

Combining data for all 45 EOFM sites in the Arkansas Discovery Farm Program highlights the importance of obtaining "realworld" losses to inform risk assessment tools and remedial policies and strategies. In table 2 , the mean annual loss of $\mathrm{N}$ and $\mathrm{P}$ from EOF sites, as a function of land use, shows a small proportion $(<5 \%)$ of applied $\mathrm{N}$ and $\mathrm{P}$ is lost as EOF runoff. The annual loss from individual sites was 0.5 to 11.8 and $<0.1$ to $2.8 \mathrm{~kg} \mathrm{ha}^{-1} \mathrm{y}^{-1}$, with an overall average of 3.2 and $0.8 \mathrm{~kg} \mathrm{ha}^{-1} \mathrm{y}^{-1}$. Analysis of data in the Measured Annual Nutrient loads from AGricultural Environments (MANAGE) database showed annual runoff losses averaged $13.1 \mathrm{~kg} \mathrm{~N} \mathrm{ha}^{-1} \mathrm{y}^{-1}$ and $2.2 \mathrm{~kg} \mathrm{P} \mathrm{ha}^{-1} \mathrm{y}^{-1}$ (Harmel et al. 2008). Putting these measured losses in a broader strategic context, they are compared with losses established during a recent US Environmental Protection study to examine the feasibility of nutrient trading scenarios among point sources and agricultural nonpoint sources (Perez et al. efforts to address agriculture's role. Harmel et Agency and World Resources Institute 
2012). Loss in surface runoff predicted by the APEX model using Natural Resources Inventory-CEAP farmer surveys from 2003 to 2006 data for "typical field management" practices, were 27.3 and $3.6 \mathrm{~kg} \mathrm{ha}^{-1} \mathrm{y}^{-1}$ for $\mathrm{N}$ and P, respectively (Perez et al. 2012).

Dale et al. (2010) and US Environmental Protection Agency (2007) recommended a $45 \%$ reduction in $\mathrm{N}$ and $\mathrm{P}$ loads to reduce the Gulf of Mexico hypoxic zone to 5,000 $\mathrm{km}^{2}$ on a five-year rolling average. Based on the US Environmental Protection Agency and World Resources Institute feasibility study that considered this reduction goal, a trading eligibility threshold of 15 and 2 $\mathrm{kg} \mathrm{N}$ and $\mathrm{P} \mathrm{ha}^{-1} \mathrm{y}^{-1}$ was established as the basis for a trading program. What is apparent is that the measured EOF losses measured under the Arkansas Discovery Farm program are below trading eligibility thresholds for both $\mathrm{N}$ and P (table 2). While the US Environmental Protection Agency-World Resources Institute was only a feasibility study, it highlighted the need for EOFM data to inform nutrient trading programs to ensure their success from an agricultural stakeholder perspective. It also highlights the need for EOFM data to inform nonpoint source models during calibration and validation steps (Harmel et al. 2014, 2016).

\section{Future of Edge-of-Field Monitoring}

While large-scale basin studies and modeling exercises are important steps in relating particular land uses to a defined in-waterbody nutrient issue, EOFM of agricultural fields provides the necessary resolution to spatially target, design, and evaluate in-field CPs for reducing nutrient loading from agriculture. Smith et al. (2018) point out the disconnect between large-scale loading estimates and the large percentage adoption of nutrient practices (4Rs), especially for fertilizer rates for row crops in the Maumee River watershed. King et al. (2018) used a network of 40 EOFM sites to look at the 4Rs of fertilizer management and was able to provide further insight and refinement to management that will help with reducing dissolved reactive P.

Kalcic et al. (2018) reviewed some the obstacles associated with using EOFM to identify the sources of nutrient runoff and evaluating progress of conservation strategies at a watershed scale. Baker et al. (2018) point out that more multiscale studies need to be conducted to find ways to connect EOFM data to watershed and in-stream water quality data if we are going to better understand the nutrient fate continuum. Similarly, Tomer (2018) suggests a twice-paired watershed experiment design to assess the effectiveness of stacked or multiple CPs on water quality mitigation.

While EOFM data can expand our understanding of the fate of nutrients applied as fertilizer, it is also the appropriate scale to engage agricultural producers in the solution process, as well as educating other producers. Several states are using Discovery Farms as a platform for education as well as routine monitoring of environmental performance. Cost is still an obstacle to widespread adoption of EOFM as an on-farm mechanism for measuring environmental performance; therefore, NRCS has recognized the importance of EOFM in adopting conservation and involving the producer in the solution process as they offer financial assistance to conduct EOFM conservation activities 201 and 202, which helps in overcoming cost issues. Harmel et al. (2018a) outline the history of EOFM along with advances in monitoring equipment, including development of lower cost techniques and addition of telemetry so that real-time results on environmental performance can be relayed to producers, which may allow for quicker adaptive management.

A novel approach of utilizing EOFM in the future may be in performance-based nonpoint source reduction strategies rather than strictly practice-based approaches. For instance, the California Agricultural Discharge program (California Environmental Protection Agency 2017) will allow agricultural producers a waiver from elements of the regulations if they can demonstrate the lack of impact on a waterbody via water quality monitoring. Perhaps EOFM someday will be used in regulatory strategies to document performance-based outcomes, instead of practice approaches if producers can demonstrate that losses from their field do not exceed a threshold. However, this prompts the question: what EOFM results are acceptable or controllable? Harmel et al. (2018b) examine this question in more detail.

\section{Disclaimer}

USDA is an equal opportunity employer and provider.

\section{References}

Alexander, R.B., R.B. Smith, G.E. Schwarz, E.W. Boyer, J.V. Nolan, and J.W. Brakebill. 2008. Differences in phosphorus and nitrogen delivery to the Gulf of Mexico from the Mississippi River Basin. Environmental Science and Technology 42:822-830.

Aryal, N., M.L. Reba, N. Straitt, T.G. Teague, J. Bouldin, and

S. Dabney. 2018. Impact of cover crop and season on nutrients and sediment in runoff water measured at the edge of fields in the Mississippi Delta of Arkansas. Journal of Soil and Water Conservation 73(1):24-34, doi:10.2489/jswc.73.1.24.

Baker, B.H., J.M. Prince Czarnecki, A.R. Omer, C.A. Aldridge, R. Kröger, and J.D. Prevost. 2018. Nutrient and sediment runoff from agricultural landscapes with varying suites of conservation practices in the Mississippi Alluvial Valley. Journal of Soil and Water Conservation 73(1):75-85, doi:10.2489/jswc.73.1.75.

California Environmental Protection Agency. 2017. Agricultural lands discharge program. State of California. http://www.waterboards.ca.gov/northcoast/ water_issues/programs/agricultural_lands/.

Dale, V.H., C.L. Kling, J.L. Meyer, J. Sanders, H. Stallworth, T. Armitage, D. Wangsness, T. Bianchi, A. Blumberg, W. Boynton, D. Conley, W. Crumpton, M. David, D. Gilbert, R.W., Howarth, R. Lowrance, K. Mankin, J. Opaluch, H. Paerl, K. Reckhow, A.N. Sharpley, T.W. Simpson, C.S. Snyder, and D. Wright. 2010. Hypoxia in the Northern Gulf of Mexico. Springer Series on Environmental Management. New York, NY: Springer Science.

Great Lakes Interagency Task Force. 2017. Great Lakes Restoration Initiative Report to Congress and the President Fiscal Years 2010-2014. Great Lakes Restoration Initiative. https://www.glri.us// pdfs/21050720-report_to_congress.pdf.

Haggard, B.E. 2010. Phosphorus concentrations, loads, and sources within the Illinois River drainage area, Northwest Arkansas, 1997-2008. Journal of Environmental Quality 39:2113-2120.

Harmel, R.D., L.E. Christianson, D.R. Smith, M.W. McBroom, and K.D. Higgs. 2016. Expansion of the MANAGE database with forest and drainage studies. Journal of the American Water Resources Association 52(5):1275-1279.

Harmel, R.D., K. King, D. Busch, D. Smith, F. Birgand, and B. Haggard. 2018a. Measuring edge-of-field water quality: Where we have been and the path forward. Journal of Soil and Water Conservation 73(1):86-96, doi:10.2489/ jswc.73.1.86.

Harmel, R.D., R.A. Pampell, A.B. Leytem, D.R. Smith, and R.L. Haney. 2018b. Assessing edge-of-field nutrient runoff from agricultural lands in the United States: How clean is clean enough? Journal of Soil and Water Conservation 73(1):9-23, doi:10.2489/jswc.73.1.9.

Harmel, R.D., S.S. Qian, K.H. Reckhow, and P. Casebolt. 2008. The MANAGE database: Nutrient load and site characteristic updates and runoff concentration data. Journal of Environmental Quality 37(6):2403-2406.

Harmel, R.D., P.K. Smith, and K.W. Migliaccio. 2010. Modifying goodness-of-fit indicators to incorporate both measurement and model uncertainty in model 
calibration and validation. Transactions of the American Society of Agricultural and Biological Engingeers 53(1):55-63.

Harmel, R.D.,P.K.Smith, K.L.Migliaccio, I.Chaubey, K.DouglasMankin, B. Benham, S. Shukla, R. Muñoz-Carpena, and B.J. Robson. 2014. Evaluating, interpreting, and communicating performance of hydrologic/water quality models considering intended use: A review and recommendations. Environmental Modeling Software 57:40-51.

Kalcic, M.,W. Crumpton, X. Liu, J. D'Ambrosio, A. Ward, and J. Witter. 2018. Assessment of beyond-the-field nutrient management practices for agricultural crop systems with subsurface drainage. Journal of Soil and Water Conservation 73(1):62-74, doi:10.2489/jswc.73.1.62.

King, K.W., M.R. Williams, G.A. LaBarge, D.R. Smith, J.M. Reutter, E.W. Duncan, and L.A. Pease. 2018. Addressing agricultural phosphorus loss in artificially drained landscapes with 4R nutrient management practices. Journal of Soil and Water Conservation 73(1):35-47, doi:10.2489/jswc.73.1.35.

Kleinman, P.J.A., A.N. Sharpley, P.J.A. Withers, L. Bergstrom, L.T. Johnson, and D.G. Doody. 2015. Implementing agricultural phosphorus science and management to combat eutrophication. Ambio 44:S297-S310.

Kröger, R., M. Perez, S. Walker, and A. Sharpley. 2012. Review of best management practice reduction efficiencies in the Lower Mississippi Alluvial Valley. Journal of Soil and Water Conservation 67(6):556-563, doi:10.2489/ jswc.67.6.556.

Louisiana Agricultural Center. 2017. Louisiana's Master Farmer program. Baton Rouge, LA: Louisiana State University Agricultural Center. http://www.lsuagcenter. com/en/environment/conservation/master_farmer/.

Maccoux M.J., A. Dove, S.M. Backus, and D.M. Dolan. 2016. Total and soluble reactive phosphorus loadings to Lake Erie: A detailed accounting by year, basin, country, and tributary. Journal of Great Lakes Research 42(6):1151-65.

Michalak, A.M., E.J. Anderson, D. Beletsky, S. Boland, N.S. Bosch, T.B. Bridgeman, J.D. Chaffin, K. Cho, R. Confesor, I. Daloglu, J.V. DePinto, M.A. Evans, G.L. Fahnenstiel, L. He, J.C. Ho, L. Jenkins, T.H. Johengen, K.C. Kuo, E. LaPorte, X. Liu, M.R. McWilliams, M.R. Moore, D.J. Posselt, R.P. Richards, D. Scavia, A.L. Steiner, E. Verhamme, D.M. Wright, and M.A. Zagorski. 2013 Record-setting algal bloom in Lake Erie caused by agricultural and meteorological trends consistent with expected future conditions. Proceedings of the National Academy of Sciences 110:6448-6452.

Minnesota Agricultural Water Resource Center. 2017. The Minnesota Discovery Farm Program. Saint Paul, MN: Minnesota Department of Agriculture. http:// www.mda.state.mn.us/protecting/cleanwaterfund/ onfarmprojects/discoveryfarmsmn.aspx.

Mississippi River/Gulf of Mexico Watershed Nutrient Task Force. 2008. Gulf Hypoxia Action Plan 2008 for Reducing, Mitigating, and Controlling Hypoxia in the Northern Gulf of Mexico and
Improving Water Quality in the Mississippi River Basin. Washington, DC: Environmental Protection Agency. https://www.epa.gov/sites/production/ files/2015-03/documents/2008_8_28_msbasin_ ghap2008_update082608.pdf.

Mississippi State University. 2017. Research and Education to Advance Conservation and Habitat, REACH. Mississippi State, MS: Mississippi State University http://www.reach.msstate.edu/.

NOAA (National Oceanic and Atmospheric Administration). 2017a. Great Lakes Harmful Algal Blooms and Hypoxia. Ann Arbor, MI: National Oceanic and Atmospheric Administration Great Lakes Environmental Research Laboratory. https://www. glerl.noaa.gov/res/HABs_and_Hypoxia/.

NOAA. 2017b. Hypoxia. Silver Spring, MD: National Oceanic and Atmospheric Administration. https:// oceanservice.noaa.gov/hazards/hypoxia/.

North Dakota State University. 2017. North Dakota Discovery Farm Program. Fargo, ND: North Dakota State University Extension. https://www.ag.ndsu.edu/df.

Nutrient Stewardship. 2017. What Are the 4Rs? Washington, DC: The Fertilizer Institute. http://www. nutrientstewardship.com/4rs/.

Osmond, D., D. Meals, D. Hoag, M. Arabi, A. Luloff, G. Jennings, M. McFarland, J. Spooner, A. Sharpley, and D. Line. 2012. Improving conservation practices programming to protect water quality in agricultural watersheds: Lessons learned from the National Institute of Food and Agriculture-Conservation Effects Assessment Project. Journal of Soil and Water Conservation 67(5):122A-127A, doi:10.2489/ jswc.67.5.122A

Perez, M., S. Walker, and C. Jones. 2012. Nutrient trading in the Mississippi River Basin: A feasibility study for using large-scale interstate nutrient trading in the Mississippi River Basin to help address hypoxia in the Gulf of Mexico. Final Report by the World Resources Institute for US Environmental Protection Agency targeted watershed grant. Washington, DC: World Resources Institute. http://www.wri.org/sites/default/files/ uploads/nutrient_trading_in_mrb_feasibility_study.pdf.

Reba, M.L., M. Daniels, Y. Chen, A.N. Sharpley, J. Bouldin, T.G. Teague, P Daniel, and C.G. Henry. 2013. A statewide network for monitoring agricultural water quality and water quantity in Arkansas. Journal of Soil and Water Conservation 68(2):45A-49A, doi:10.2489/ jswc.68.2.45A.

Robertson, D., and D. Saad. 2011. Nutrient inputs to the Laurentian great lakes by source and watershed estimated using SPARROW watershed models. Journal of the American Water Resources Association 47(5):1011-1033.

Scavia D., J.V. DePinto, and I. Bertani. 2016. A multi-model approach to evaluating target phosphorus loads for Lake Erie. Journal of Great Lakes Research 42(6):1139-50.
Schindler, D.W., R.E. Hecky, D.L. Findlay, M.P. Stainton, B.R. Parker, M.J. Paterson, K.G. Beaty, M. Lyng, and S.E.M. Kasian. 2008. Eutrophication of lakes cannot be controlled by reducing nitrogen input: Results of a 37-year whole-ecosystem experiment. Proceedings of the National Academy of Sciences 106:11254-11258.

Sharpley, A.N., M.B. Daniels, L. Berry, and C. Hallmark. 2015. Discovery Farms: Documenting water quality benefits of on-farm conservation management and empowering farmers. Acta Agriculturae Scandinavica, Section B - Soil Plant Science 65(Suppl. 2):186-198.

Sharpley, A., M. Daniels, L. Berry, C. Hallmark, and L. Riley. 2016a. Proactive stakeholder program determines on-farm effectiveness of conservation practices that increases fertilizer-use efficiency. Better Crops 100(3):13-15.

Sharpley, A.N., H.P. Jarvie, A. Buda, L. May, B. Spears, and P.J.A. Kleinman. 2013. Phosphorus legacy: Overcoming the effects of past management practices to mitigate future water quality impairment. Journal of Environmental Quality 42:1308-1326.

Sharpley, A.N., P.J.A. Kleinman, H.P. Jarvie, and D. Flaten. 2016b. Distant views and local realities: The limits of global assessments to restore the fragmented phosphorus cycle. Agricultural and Environmental Letters 1:160024, doi:10.2134/ael2016.07.0024.

Sharpley, A.N., P.J.A. Kleinman, P. Jordan, L. Bergström, and A.L. Allen. 2009. Evaluating the success of phosphorus management from field to watershed. Journal of Environmental Quality 38(5):1981-1988.

Sharpley, A.N., A. Shirmohammadi, and T. Walter. 2010. Targeting risky management in vulnerable landscapes. In Managing Agricultural Landscapes for Environmental Quality II: Achieving More Effective Conservation, eds. M. Schnepf and P. Nowak, 51-68. Ankeny, IA: Soil and Water Conservation Society.

Shirmohammadi, A., I. Chaubey, R.D. Harmel, D.D. Bosch, R. Muñoz-Carpena, C. Dharmasri, A. Sexton, M. Arabi, M.L.Wolfe, J. Frankenberger, C. Graff, and T.M. Sohrabi. 2006. Uncertainty in TMDL models. Transactions of the American Society of Agricultural and Biological Engineers 49(4):1033-1049.

Smith D.R., R.S. Wilson, K.W. King, M. Zwonitzer, J.M. McGrath, R.D. Harmel, R.L. Haney, and L.T. Johnson. 2018. Lake Erie, phosphorus, and microcystin: Is it really the farmer's fault? Journal of Soil and Water Conservation 73(1):48-57, doi:10.2489/jswc.73.1.48.

Tomer, M.D. 2018. A twice-paired watershed experimental design to assess stacked practices through field-edge monitoring. Journal of Soil and Water Conservation 73(1):58-61, doi:10.2489/jswc.73.1.58.

Tomer, M.D., and M.A. Locke. 2011. The challenge of documenting water quality benefits of conservation practices: A review of USDA-ARS's conservation effects assessment project watershed studies. Water Science and Technology 64(1):300-310. 
USDA NRCS (Natural Resources Conservation Service). 2013a. Natural Resources Conservation Service edgeof-field water quality monitoring data collection and evaluation - conservation activity (Code 201). https:// www.nrcs.usda.gov/Internet/FSE_DOCUMENTS/ stelprdb1097617.pdf.

USDA NRCS. 2013b. Natural Resources Conservation Service edge-of-field water quality monitoring system installation - conservation activity (Code 202). https:// www.nrcs.usda.gov/Internet/FSE_DOCUMENTS/ stelprdb1097618.pdf.

US Environmental Protection Agency. 2007. Hypoxia in the Northern Gulf of Mexico. Washington, DC: US Environmental Protection Agency, Science Advisory Board. http://yosemite.epa.gov/sab/sabproduct.nsf/ c3d2f27094e03f90852573b800601d93/\$file/epa-sab08-003complete.unsigned.pdf.

University of Arkansas Division of Agriculture. 2017. The Arkansas Discovery Farm Program. Fayetteville, AR: University of Arkansas. http://discoveryfarms.uark.edu/.

University of Wisconsin Extension. 2017. The Wisconsin Discovery Farm Program. Pigeon Falls, WI: University of Wisconsin Extension. http://www.uwdiscoveryfarms.org/.

Veith, T.L., J.E. Richards, S.C. Goslee, A.S. Collick, R.B. Bryant, D.A. Miller, B.W. Bills, A.R. Buda, R.L. Sebring, and P.J.A. Kleinman. 2015. Navigating spatial and temporal complexity in developing a long-term land use database for an agricultural watershed. Journal of Soil and Water Conservation 70(5):288-296, doi:10.2489/ jswc.70.5.288.

White, M.J., C. Santhi, N. Kannan, J.G.Arnold, R.D. Harmel, L. Norfleet, P. Allen, M. DiLuzio, X. Wang, J. Atwood, E. Haney, and M. Johnson. 2014. Nutrient delivery from the Mississippi River to the Gulf of Mexico and effects of cropland conservation. Journal of Soil and Water Conservation 69(1):26-40. 